$\begin{gathered}\text { EPiC Series in Built Environment } \\ \text { Volume 2, 2021, Pages 606-614 }\end{gathered}$
ASC 2021. 57th Annual Associated Schools
of Construction International Conference

\title{
Recent Energy Consumption Trends in American Homes
}

\author{
Luciana Debs, Ph.D. and Bhavya Rathna Kota \\ Purdue University \\ West Lafayette, IN
}

\author{
Jamie Metzinger, Ph.D. \\ Indiana State University \\ Terre Haute, IN
}

Given the growing environmental awareness, this paper intends to provide an updated picture on the relationships between 1) demographic factors and number of residential sustainable features (mainly appliances), 2) demographic factors and energy consumption (for all fuels), and 3) house size and energy consumption in American households. Using data from the 2015 Residential Energy Consumption Survey (RECS), this study applies descriptive and inferential statistics (poisson regression, spearman correlation and analysis of variance) to evaluate those relationships. The results indicate that income influences the number of sustainable appliances in a home, while education does not; on the other hand, the findings also indicate that education has a significant relationship to energy consumption (measured in thousand BTUs) per area of home, while income does not. Additionally, a significant moderate correlation between size of home and energy consumption was confirmed. This information is important given the steady but constant rise in home sizes in the U.S. since 1970s. Outcomes of this study can help understand the impact of demographic factors have on sustainable housing choices and on energy consumption while using a recent data set with large sample size.

Keywords: sustainability trends, consumer behavior, energy consumption, RECS suvey, residential construction

\section{Introduction}

Events in the second half of the $20^{\text {th }}$ century, such as the rapid economic development and urbanization, the 1970s energy crisis, and the realization of environmental impacts of fossil fuels have raised the awareness of Americans towards environmental issues and the hazardous impacts of human activities on the environment (Durand \& Sharma, 1982; Erten, Korkmaz, Syal, \& Potbhare, 2009). To help manage and curtail the energy consumption demand, the United States (U.S.) government introduced regulatory policies and incentives like tax benefits for households that lower the end-use energy consumption or install renewable energy sources (DSIRE, 2020). The combination of homeowners' increased awareness and concern over the environment, the increasing energy costs, and the introduction of government incentives for the use of more environmentally friendly options seemed to have influenced householders' energy-saving behavior (Barr, Gilg, \& Ford, 2005; Poortinga, Steg, Vlek, \& Wiersma, 2003). 
As a result, many studies were conducted to understand the relationship between purchasing behavior and consumers' attitude and awareness of environmental and social issues. And, while some studies have found signs of a shift in consumer behavior towards more responsible consumerism (Moser, 2015), others found that the willingness of consumers to be responsible are influenced by some demographic factors like education level, financial status or level of income, geographical location among others (Moser, 2015; WBCSD, 2008).

Still, in 2019 the residential sector in the U.S. consumed over one-fifth (21.4\%) of total energy consumption in the country - noted that this number also includes large energy losses in the transmission system. Additionally, U.S. homes are mostly fueled by electricity and natural gas. Renewable energy sources - geothermal, biomass, and solar - have displayed a slight increase since 2012, but remains only $3.9 \%$ of the total energy consumed by the residential sector (U.S. Energy Information Administration, 2021).

Despite residential energy conservation efforts, this high amount of energy use can be linked to modernization, growing population, and higher living standards, which results in more consumers using electronic appliances and space conditioning systems in U.S. households (Kaza, 2010). And, for the energy use in residences, factors like climate, the number of appliances, size of the house, and the number of household members also influence the demand (U.S. Energy Information Administration, 2021).

Even though consumption might still be high, recent data from the U.S. residential sectors show decreased energy use per household than the previous years' data, which is encouraging (U.S. Energy Information Administration, 2021). Though the higher standard of living results in consumers using more electronic appliances and space conditioning systems (Kaza, 2010), other factors such as technology improvement for home appliances and equipment, the number of energy-efficient appliances, and good insulation can also reduce the energy consumption per household trend mentioned above (Metcalf \& Hassett, 1999). According to Gardner and Stern (2010), changing appliances or upgrading to current technologies can significantly reduce the energy consumption in households. This is because appliances and building equipment and systems like lighting, water heaters, refrigerators, and electric motors account for almost $90 \%$ of the total household energy use (Hampton, Okpala, Perez-Reyes, Roycroft, \& Sowards, 2017). In other words, the number of sustainable features present in the house and the imposition of updated building codes, such as having minimum standards of appliance efficiency may influence household energy consumption (Aroonruengsawat, Auffhammer, \& Sanstad, 2012).

From a research perspective on residential energy conservation, finding the number of sustainable appliances is important, but the installation of these appliances is based on voluntary efforts of the household. This is still the case even with the presence of incentives and rebates for purchasing Energy Star certified appliances. Previous research has been conducted to assess what influences the household behavior or the intention to purchase or install sustainable features, and some of these determinants are the influence of policies and incentive programs, benefits of using energy-efficient appliances, household consumer attitude, environmental concern, and demographic factors like level of education, household income influences energy-saving behavior in a household (Ketchman et al., 2018; Ohler, Loomis, \& Ilves, 2020). However, studies indicate that the transition of the purchasing intention to actual purchasing behavior as the transition is not perfect and since most of these studies are based on consumer theories, it is important to get factual data to back these theories. To this point, the authors propose an analysis of the latest Residential Energy Consumption Survey (RECS) data available, to assess the influence of certain demographic data on households' actual purchasing behavior of sustainable home appliances and on its energy consumption; and of home size to energy consumption. Findings from the present study can inform construction professionals, instructors, and 
students to better understand the impact of housing choices can have on energy consumption as well as verify the emergence of more sustainable features trends related to residential buildings.

\section{$\underline{\text { RECS Survey }}$}

The first RECS survey was conducted in 1978 and its latest (fourteenth) iteration was conducted in 2015. The survey is administered by the United States Energy Information Administration (US EIA). Questions and methodology for the survey are constantly reviewed and updated to understand the household characteristics, consumption, and expenditure patterns across the country. RECS microdata, as well as general information is available for public download (U.S. Energy Information Administration, 2021). For the 2015 survey used in this study, the sampling design adopted was a national wide multistage area probability sample design (from large geographical area to individual housing unit) and the recruitment of participants was through interviews, web, and mail forms. To maintain the quality of the data several statistical processes like editing, validation, and quality control, and imputation of missing data are performed to ensure precise findings on trends (U.S. Energy Information Administration, 2021).

Previous research published on data from RECS also provides an interesting baseline. Among those, the authors note the ones that closely relate to the present inquiry, such as a modest correlation between income and electricity usage, though the range varied greatly in most of the income brackets in 2005 (Sanquist, Orr, Shui, \& Bittner, 2012), and indirect influence of household characteristics on the energy consumption, but direct influence over housing unit characteristics using 2009 RECS data (Estiri, 2014). And, as noted, most of the research utilized data from RECS survey before 2010 . The 2015 data was released to the public in December 2018 and may present different trends, which is provided in the present study.

\section{Methodology}

In this study, only data from the RECS survey for owner-occupied units was used, given that tenants have little control over some of the significant equipment utilized in a home. The analysis includes descriptive and inferential statistics. First, descriptive statistics for key features of the home and household are provided, such as type of home, year built, number of household members, education level of respondent, annual gross household income in 2014 and sustainable features in home.

Then, the influence of select demographic factors, namely education and household income, on the actual purchasing behavior of sustainable features is assessed. The nine sustainable features selected to be analyzed in the present research are energy start qualified clothes washer, clothes dryer, dishwasher, freezer, refrigerator, lightbulb, water heater, windows, and smart thermostat. Because the dependent variable is in count data, a poisson regression at the 5\% confidence level was performed. The model used also included the total number of applicable features in a home to account for homes that do not have certain of the features (such as freezer, dishwasher or other). "Not applicable" and "refused to respond" responses were excluded from the total number of features analyzed, and "don't know" was considered as a "not sustainable".

Thirdly, a correlation analysis between total energy consumption (measured in thousand BTUs) and house size using a Spearman correlation statistics was conducted. While it is expected that there is a strong correlation between size and energy consumption, the authors were interested in assessing the graphical distribution of the data, especially as house sizes grow larger. This also provides additional 
information to compare with the statement from RECS about the decrease of energy consumption per household (U.S. Energy Information Administration, 2021).

Finally, the authors evaluated the relationship between respondents education and annual gross household income towards a household's energy consumption (in thousand BTUs) per square footage. A two-way ANOVA analysis at the 5\% confidence level was used in testing this hypothesis.

\section{Results}

\section{Descriptive Statistics}

The total numer of surveyed households in RECS 2015 was 5,686, and of those 3,928 were owneroccupied and object of the present study. Of those, the vast majority $(83.7 \%)$ are single-family detached houses, as seen in figure 1 . The sample also has similar number of houses within the stipulated ranges for year built. Yet, most surveyed houses were built between 2000 and 2010 $(\mathrm{n}=16.62 \%)$, followed by houses built between 1970 and $1979(\mathrm{n}=15.45 \%)$, then between 1990 and $1999(\mathrm{n}=15.35 \%), 1980$ and $1989(\mathrm{n}=14.69 \%)$, before $1950(\mathrm{n}=14.56 \%), 1950$ and $1959(\mathrm{n}=9.90 \%)$, 1960 and $1969(\mathrm{n}=9.65 \%)$, and finally between 2010 and $2015(\mathrm{n}=3.77 \%)$.

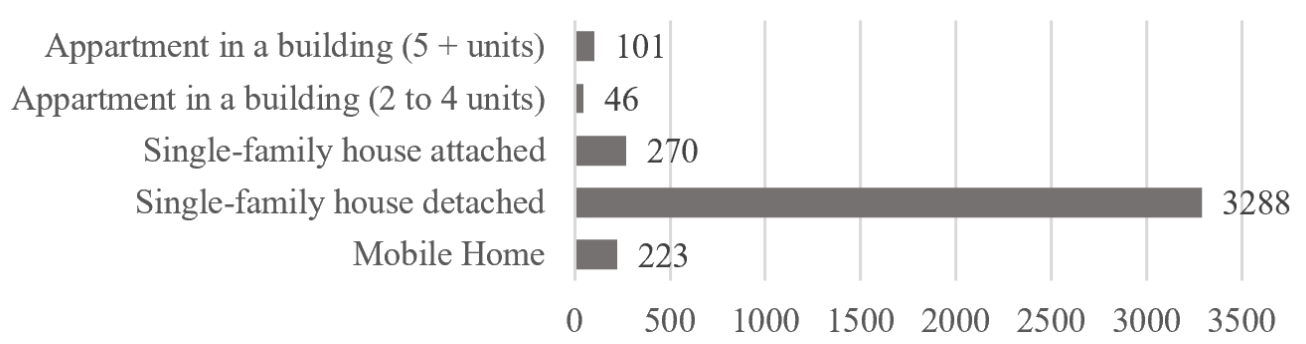

Figure 1. Type of houses (total $n=3928$ )

As for household demographics, the authors have analyzed (a) the number of household members, (b) educational level of respondent, and (c) annual household income for 2014. For number of household members, it was found that the vast majority of households is comprised of two people accounting for almost half of respondents $(\mathrm{n}=40.48 \%)$, followed by households of one person $(\mathrm{n}=19.60 \%)$, three people $(n=16.14 \%)$, four people $(n=13.47 \%)$, five people $(n=6.44 \%)$, six people $(n=2.42 \%)$ and finally seven or more people (1.45\%). For education, figure 2 shows the summary of answers. Most respondents indicated they have some college or Associate's degree $(n=32.38 \%)$, followed by high schoold diploma or GED ( $\mathrm{n}=22.58 \%)$, bachelor's degree $(22.10 \%)$, master's, professional or doctorate degree $(n=17.16 \%)$ and finally, less than high school diploma or GED $(n=5.78 \%)$. The authors acknowledge that the results of the present study is limited to information provided from RECS related to education, which is only the highest degree earned by the respondent. Therefore, the information might not provide a full picture of the education level of each household member. Finally, many households $(n=20.01 \%)$ are included in the $\$ 20,000$ and $\$ 39,999$ annual gross income, and the least number of households are included in the $\$ 120,000$ and $\$ 139,999$ range $(n=6.26 \%)$. Figure 3 provides the breakdown per bracket included in the RECS survey. The annual gross income is based on household income for the year of 2014. 


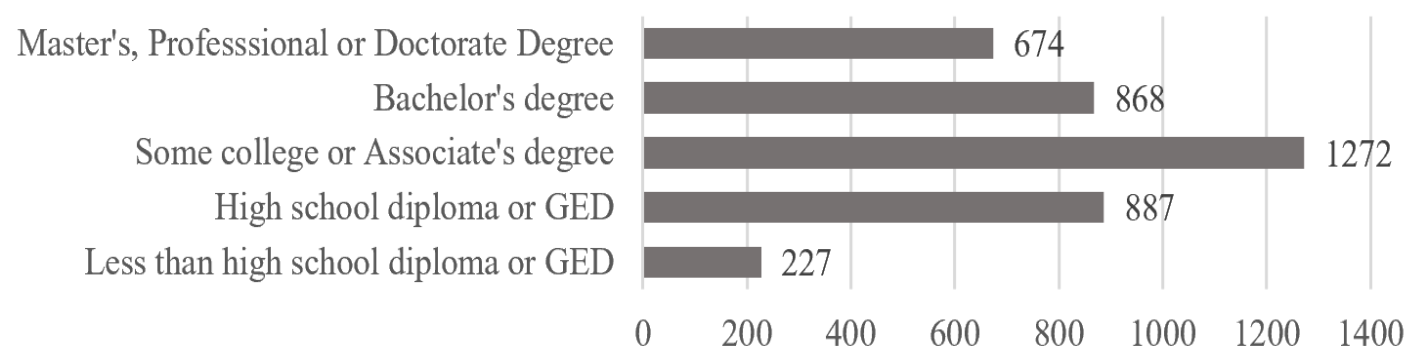

Figure 2. Education Level of respondents (total $n=3928$ )

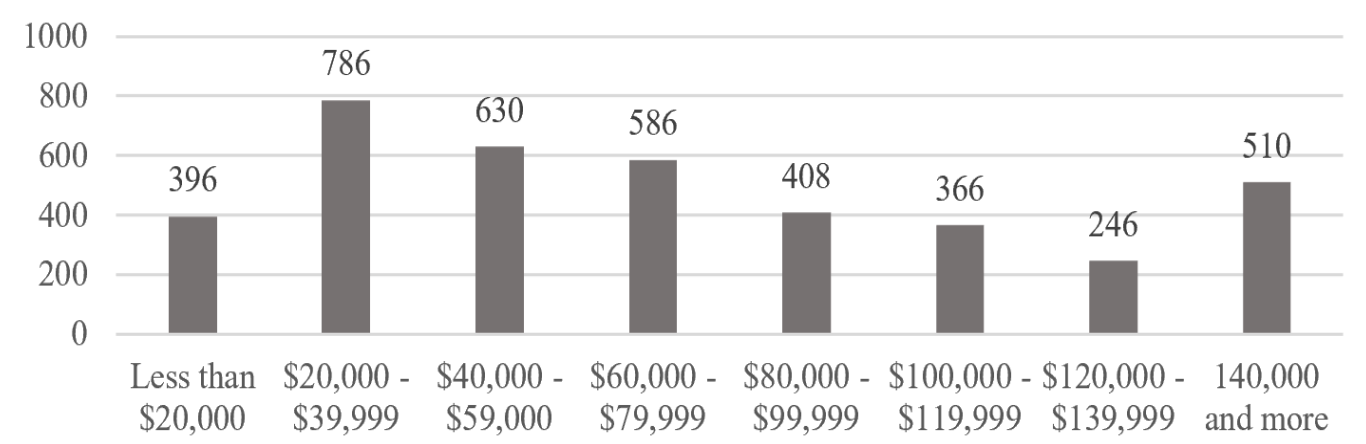

Figure 3. Annual Gross Income of Household in 2014 (total $n=3928$ )

Descriptive statistics for the nine sustainable features is also provided in this paper. Results show that refrigerators are the most likely to be energy star qualified $(n=55.07 \%)$, while many respondents indicated they do not have Energy Star qualified windows $(n=55.70 \%)$ or have smart thermostats $(\mathrm{n}=4.58 \%)$. As noted previously, some respondents do not have certain appliances (not applicable), refused to answer, or do not know if their appliances are Energy Star qualified (or if they have a smart thermostat), as can be seen in table 1 .

Table 1

Sustainable features descriptive statistics (total $n=3928$ )

\begin{tabular}{lccccc}
\hline Sustainable Feature & Yes & No & $\begin{array}{c}\text { Not } \\
\text { applicable }\end{array}$ & Refused & $\begin{array}{c}\text { Don't } \\
\text { know }\end{array}$ \\
\hline Energy Star qualified clothes & 1950 & 1414 & 122 & 70 & 372 \\
washer & 1490 & 1267 & 851 & 42 & 278 \\
Energy Star qualified dishwasher & 1739 & 1576 & 180 & 67 & 366 \\
Energy Star qualified clothes dryer & 575 & 883 & 2296 & 26 & 148 \\
Energy Star qualified freezer & 2163 & 1277 & 17 & 76 & 395 \\
Energy Star qualified refrigerator & 1800 & 1656 & - & 76 & 396 \\
Energy Star qualified lightbulbs & 1557 & 1892 & - & 76 & 403 \\
Energy Star qualified water heating & 1234 & 2188 & - & 76 & 430 \\
Energy Star qualified windows & 180 & 3337 & 270 & 0 & 141 \\
Smart thermostat & & & & & \\
\hline
\end{tabular}




\section{Inferential Statistics}

First, the authors have analyzed the relationship between income and education towards the number of sustainable features in a home, while controlling for the total number of features. A Poisson

Regression model was used. The model displayed a slight dispersion (dispersion parameter $=4.77$ ), but was deemed adequate for the analysis. Results from the Poisson regression showed that there is a statistical significance for the relationship between annual gross income in 2014 and sustainable features ( $p$-value $<0.01$ ), but it did not show a statistical relationship between education and sustainable features $(\mathrm{p}$-value $=0.09)$. Table 2 provides a summary of the test results.

Table 2

Poisson regression results

\begin{tabular}{lcccc}
\hline Source & Estimate & Std. Error & T-value & Sig \\
\hline Intercept & -7.444891 & 0.063727 & -116.824 & $<0.001$ \\
Education & 0.033196 & 0.019644 & 1.690 & 0.0911 \\
Annual Gross Income (2014) & 0.039274 & 0.009862 & 3.982 & $<0.001$ \\
\hline
\end{tabular}

As part of the present study, a correlation analysis between house square footage and total BTUs (in thousands) consumed per household was conducted. As predicted, the correlation is significant at the $\mathrm{p}<0.01$ and is moderate at $\mathrm{r}_{\mathrm{s}}=0.502$. In addition, the measure thousand BTUs per square footage of construction varies from a minimum of 1.14 to a maximum of 277.75 , it has a mean of $\bar{x}=41.54$ and standard deviation of $\mathrm{SD}=23.20 \mathrm{BTUs} / \mathrm{square}$ footage. Figure 4 shows the scatterplot for total BTU (in thousands) per square foot of home, showing data is very dense up to about 4,000 sqft homes, with data spreading more after that, while the average house size (owner occupied homes) is 2,458.7 sqft.

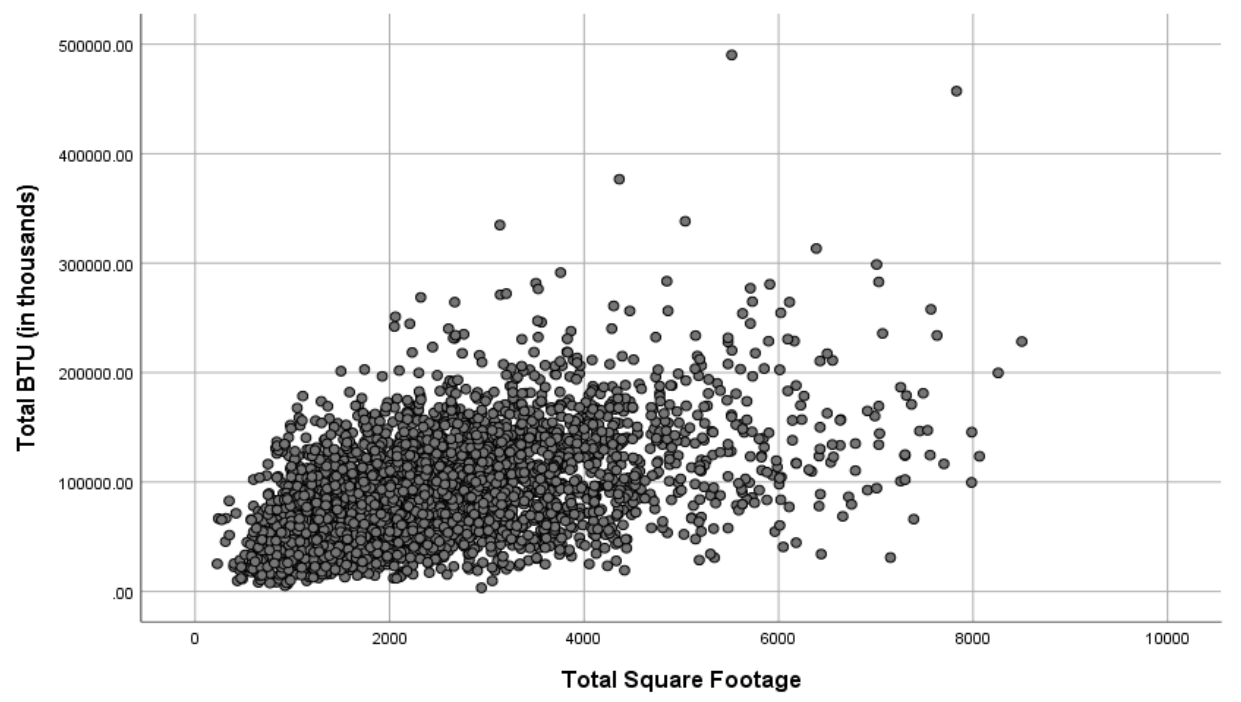

Figure 4. Scatterplot of Total BTUs (in thousands) per square foot of home

Finally, the authors have analyzed the relationship between income and education to the energy consumption (in thousand BTUs) per square foot of house using a two-way Anova analysis. The dependent variable had to undergo a Box Cox transformation to improve fit for constant variance still, the authors note that this assumption was not completely sastisfied and there might slight bias in the results. The results show that it is possible to reject the null hypothesis and accept the alternate 
alternate model indicating a significant relationship between annual gross income (INCOME) and respondent's education (EDUCATION) towards energy consumption per square foot ( $\mathrm{F}=2.241$, $\mathrm{p}$ value $<0.001$ ). Additionally, the authors have evaluated each main factor (INCOME and EDUCATION), as well as the interaction effect between both as indicated in Table 3.

Table 3

Two-way ANOVA results

\begin{tabular}{lcccc}
\hline Source & Type III Sum of Squares & Df & F & Sig \\
\hline Corrected Model & 84.559 & 39 & 2.241 & .000 \\
Intercept & 16242.028 & 1 & 16789.423 & .000 \\
Income & 5.571 & 7 & .823 & .568 \\
Education & 22.658 & 4 & 5.855 & .000 \\
Income*Education & 22.940 & 28 & .847 & .696 \\
Error & 3761.237 & 3888 & & \\
Total & 101481.808 & 3928 & & \\
Corrected Total & 3845.796 & 3927 & & \\
\hline
\end{tabular}

The main factors' analysis shows the interaction effect between income and education is not significant ( $\mathrm{p}$-value $=0.696$ ), as well as income is not significantly related to energy consumption ( $\mathrm{p}$ value $=0.568$ ). On the other hand, education was shown to be a significant factor ( $p$-value $<0.001$ ). Which is an interesting finding, given that the analysis for the number of sustainable features in a home seems to be significantly related to income, but not to education. Some limitations apply to this analysis, in that education levels are per respondent and may not accurately reflect education level of all household members. Additionally, further analysis of estimated marginal means indicates high variance for the lowest bracket of the education factor ("less than high-school diploma or GED"), as shown in figure 5 , while other brackets seem to follow a similar pattern.

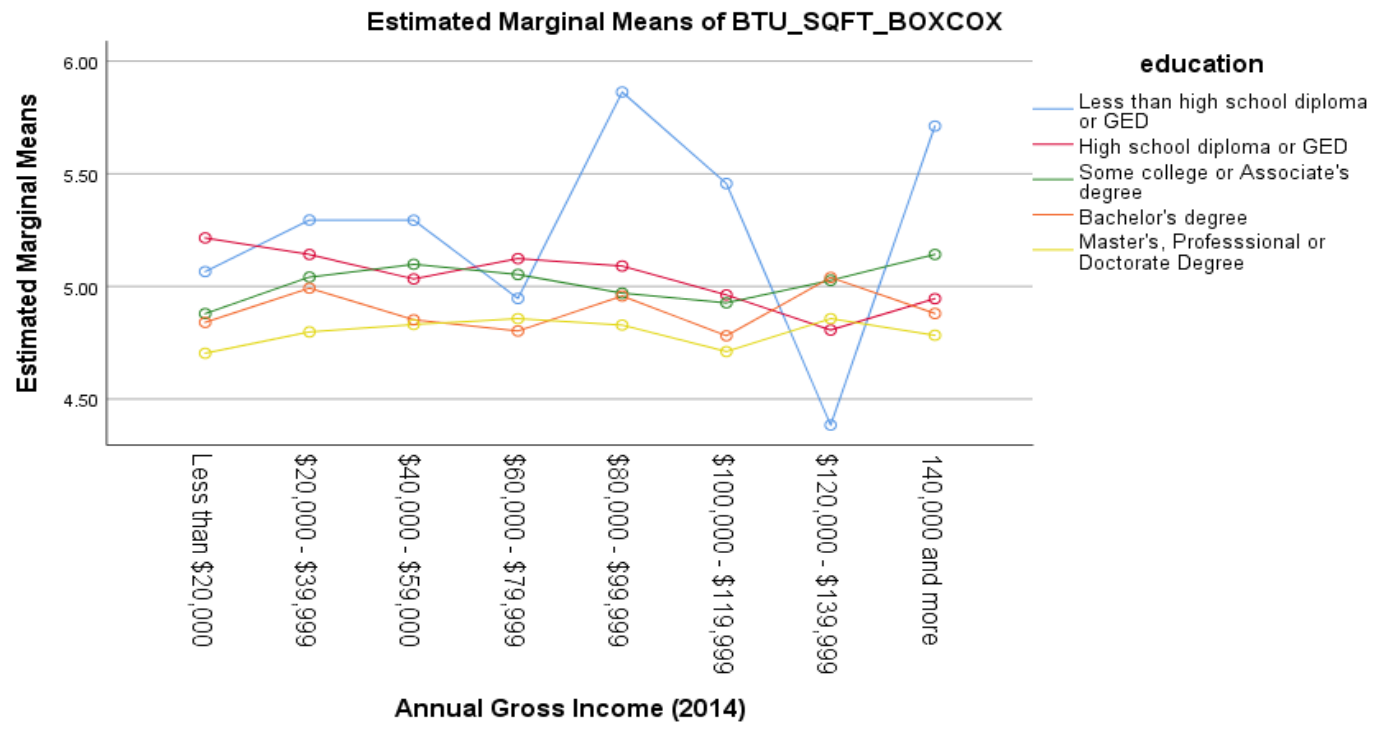

Figure 5. Estimated Marginal Means for the two-way ANOVA analysis 


\section{Discussion and Conclusion}

The results from the present study suggest that home size is moderately correlated with energy use in home, which was expected and consistent with previous research findings (Steemers \& Yun, 2009). Although not unexcpected, this information is relevant, given the rise in size of the American home since 1970 (U.S. Energy Information Administration, 2021). Therefore, it is expected that residential energy consumption has also increased since then. Thus suggesting that rethinking the size of the average american home can significantly affect residential energy consumption.

Also, the present results differ to those of Sanquist et al (2012), in that no significant relationship between income and energy consumption was found. However, the authors note that the present tests are based in total energy (including electricity, gas, propane and fuel oil / kerosene) and evaluate energy per square-feet of construciton, while Sanquist et al. only evaluated electricity and electricfueled appliances. Additionally, the present study's results also differ from those of Ohler et. al (2020), who again just evaluated electricity consumption, and found education not to be a significant factor in electricity consumption, while income was (with more energy consumed). The present paper results, however, do concur with Ohler et al. (2020)'s suggestion that households with higher income may own more energy star appliances.

In conclusion, results from the present study are based on a large sample from the RECS 2015 survey and indicate that size directly contributes to the amount of energy consumed in a home, and income has a significant influence on the number of energy star appliances (or smart thermostat) included in a home, but it is not significantly related to the energy consumption per square foot of the home (considering all types of fuel used). And, while education is shown to have a significant influence on the amount of energy consumed per square foot of house, it does not significantly influence the number of energy start appliances (or smart thermostat) owned in a home. Futhermore, the present analysis uses a combination of all fuels used in a home, which can provide a more acurate analysis of the energy consumption, given the large scale use of natural gas in american households. These results also provide an interesting and updated panorama of energy usage of american, owner-occupied households.

Further studies may explore further on the impact of energy star appliances and energy consumption given the conflicting findings of the present study, to explore further the differences in the significance of education and income in those two analysis. Additionally, the authors suggest further studies to evaluate the change over time in energy consumption per square foot of home, as well as variations of energy consumption based on income and education.

\section{References}

Aroonruengsawat, A., Auffhammer, M., \& Sanstad, A. H. (2012). The impact of state level building codes on residential electricity consumption. Energy Journal, 33(1), 31-52.

Barr, S., Gilg, A. W., \& Ford, N. (2005). The household energy gap: Examining the divide between habitual- and purchase-related conservation behaviours. Energy Policy, 33(11), 1425-1444.

DSIRE. (2020, February 13). Residential Renewable Energy Tax Credit. Retrieved November 19, 2020, from DSIRE website: https://programs.dsireusa.org/system/program/detail/1235

Durand, R. M., \& Sharma, S. (1982). Conservation or energy development: Consumer perceptions of 
alternate solutions to the energy crisis. Journal of the Academy of Marketing Science, 10(4), 410-431. https://doi.org/10.1007/BF02729344

Erten, D., Korkmaz, S., Syal, M., \& Potbhare, V. (2009). A Review of Green Building Movement Timelines in Developed and Developing Countries to Build an International Adoption Framework . Collaboration and Integration in Engineering, Management and Technology, 1-9.

Estiri, H. (2014). Building and household X-factors and energy consumption at the residential sector. A structural equation analysis of the effects of household and building characteristics on the annual energy consumption of US residential buildings. Energy Economics, 43, 178-184.

Gardner, G. T., \& Stern, P. C. (2010). Environment: Science and Policy for Sustainable Development The Short List: The Most Effective Actions U.S. Households Can Take to Curb Climate Change. Environment: Science and Policy for Sustainable Development, 50(5), 12-25.

Hampton, R., Okpala, A., Perez-Reyes, M., Roycroft, D., \& Sowards, S. (2017). Fact Sheet - Energy Efficiency Standards for Appliances, Lighting and Equipment (2017) . Retrieved November 20, 2020, from Environmental and Energy Study Institute website: https://www.eesi.org/papers/view/fact-sheet-energy-efficiency-standards-for-applianceslighting-and-equipmen

Kaza, N. (2010). Understanding the spectrum of residential energy consumption: A quantile regression approach. Energy Policy, 38(11), 6574-6585.

Ketchman, K. J., David, ;, Riley, R., Khanna, V., Bilec, M. M., \& Asce, A. M. (2018). Survey of Homeowners' Motivations for the Adoption of Energy Efficiency Measures: Evaluating a Holistic Energy Assessment Program. Journal of Architectural Engineering, 24(4), 040180241-04018024-12.

Metcalf, G. E., \& Hassett, K. A. (1999). Measuring the energy savings from home improvement investments: Evidence from monthly billing data. Review of Economics and Statistics, 81(3), $516-528$.

Moser, A. K. (2015). Thinking green, buying green? Drivers of pro-environmental purchasing behavior. Journal of Consumer Marketing, 32(3), 167-175.

Ohler, A. M., Loomis, D. G., \& Ilves, K. (2020). A study of electricity savings from energy star appliances using household survey data. Energy Policy, 144, 111607.

Poortinga, W., Steg, L., Vlek, C., \& Wiersma, G. (2003). Household preferences for energy-saving measures: A conjoint analysis. Journal of Economic Psychology, 24(1), 49-64.

Sanquist, T. F., Orr, H., Shui, B., \& Bittner, A. C. (2012). Lifestyle factors in U.S. residential electricity consumption. Energy Policy, 42, 354-364.

Steemers, K., \& Yun, G. Y. (2009). Household energy consumption: A study of the role of occupants. Building Research and Information, 37(5-6), 625-637.

U.S. Energy Information Administration. (2021). Residential Energy Consumption Survey (RECS). Retrieved January 5, 2021, from https://www.eia.gov/consumption/residential/

WBCSD. (2008). Sustainable consumption facts \& trends . Retrieved November 19, 2020, from World Business Council for Sustainable Development website: https://www.wbcsd.org/Programs/People/Sustainable-Lifestyles/Resources/Sustainableconsumption-facts-trends 